\title{
Interactive comment on "Understanding mercury oxidation and air-snow exchange on the East Antarctic Plateau: A modeling study" by Shaojie Song et al.
}

Shaojie Song et al.

shaojie.song@gmail.com

Received and published: 26 September 2018

Please find the responses in the attached pdf file.

Please also note the supplement to this comment: https://www.atmos-chem-phys-discuss.net/acp-2018-436/acp-2018-436-AC1supplement.pdf 2018. 